\title{
Travel restrictions in the rising COVID-19 pandemic
}

\author{
William Xue *, Cynthia Lam, HH Yeung, CS Wong, Venus LY Chan, YS Wong
}

Faculty of Medicine, The Chinese University of Hong Kong, Hong Kong

*Corresponding author: wxue@link.cuhk.edu.hk

Hong Kong Med J 2020;26:255-7

https://doi.org/10.12809/hkmj208554

The first reported case of coronavirus disease 2019 (COVID-19) dates to November 2019 at Wuhan, China. It has since spread domestically and internationally, with cases exported via land, sea, and air travel. On 25 January 2020, the Hong Kong government raised the response level under the "Preparedness and Response Plan for Novel Infectious Disease of Public Health Significance" to Emergency Response Level. ${ }^{1}$ This response level implies a high and imminent threat to the health of the local population, and public health measures were initiated accordingly. ${ }^{2}$ Initial measures included case isolation, quarantine, and medical surveillance of close contacts. ${ }^{3}$ From 3 February, all border crossings to and from Hong Kong were closed, except for Hong Kong International Airport, Shenzhen Bay Bridge, and Hong Kong-ZhuhaiMacao Bridge. ${ }^{4}$ Many from the general public and the healthcare industry demanded further actions as the Hospital Authority Employees Alliance organised a strike to pressure the government into ordering a total border shutdown. ${ }^{5}$ On 25 March, extensive immigration restrictions were implemented in view of the spreading global pandemic. Non-residents arriving in Hong Kong by air were denied entry, and all travellers coming from mainland China, Macao, or Taiwan were subject to a 14-day compulsory home quarantine. ${ }^{6}$ These measures are in accordance with Article 18 of the International Health Regulations, ${ }^{7}$ in which the World Health Organization recommends "restrictions on persons from affected areas" as a potential means to reduce the international spread of disease, while avoiding unnecessary interference with international traffic.

The implementation of public health measures is dependent on local context, balancing risks and benefits. Nonetheless, our knowledge on the ongoing pandemic is inevitably limited. The reproduction number $\mathrm{R}_{0}$ of COVID-19 is under debate, with the World Health Organization's preliminary estimate of 1.4 to $2.5^{8}$ challenged by Liu et al, ${ }^{9}$ who calculated an average of 3.28. The efficacy of closing borders compared with inaction or other forms of travel restrictions in the containment of respiratory zoonotic viral infections with documented personto-person transmission has been well discussed in the literature.

Travel restrictions typically have a limited effect in rapidly containing infections within a defined geographical area. ${ }^{10}$ When implemented extensively (>90\%), these restrictions can delay the national spread, global spread, and peak of an epidemic, but effects on mitigating the magnitude of pandemics are limited. The spread is negatively correlated with the strain's transmissibility, while favourable factors include timely initiation, a longer period of implementation, and certain geographical sources. ${ }^{10}$ Other public health measures are typically recommended, when considering their implementation in isolation, such as providing information to travellers, health monitoring, improving community hygiene, and school or work closures. ${ }^{11,12}$

Although extensive travel restrictions pose resource burdens, they provide additional value in reducing attack rates when combined with other interventions. Cooper et $\mathrm{al}^{13}$ found that, although suspension of $99.9 \%$ of air travel would only be able to delay the spread of the disease to an individual nation for $\leq 4$ months, combining this with other local strategies, such as stocking up antivirals and case quarantine, would allow a $\leq 10$-month delay of pandemic spread and reduction of transmission of $40 \%$. Meanwhile, Chong and Zee ${ }^{14}$ compared the effect of travel restrictions coupled with antiviral use and hospitalisation, showing that despite a $<10 \%$ mitigation of epidemic magnitude by individual measures, together they bring synergy and result in a 6-week delay. Therefore, the efficacy of travel restrictions should be considered in combination instead of in isolation.

There is heterogeneity in outcome measures between reviews. For example, Mateus et $\mathrm{al}^{10}$ took a quantitative approach, measuring the days of delay in epidemic peaks, pandemic spread, or magnitude of the spread; whereas Huizer et $\mathrm{al}^{11}$ took a qualitative approach, allocating arbitrary scores in a framework that comments on the efficacy and feasibility of different measures. Thus, in the context of COVID-19, "preventing or delaying the spread" or "flattening the curve" should be placed at a higher priority than "containing the virus", so as to provide 
a buffer for institutions to better prepare for the epidemic, for example by preparing isolation wards, sourcing and stocking up on necessary personal protective equipment for frontline healthcare professionals, or developing and producing treatments or vaccines. ${ }^{14}$

A major limitation of mathematical models is that they cannot perfectly replicate real-life scenarios. Simulations can also be subject to bias in terms of study design and assumptions, as well as the credibility of the input data. For example, a probabilistic mathematical study on Pacific Island Countries and Territories by Eichner et $\mathrm{al}^{15}$ assumed that voluntary travel volume decreases as people get increasingly sick. This might not be the case for Hong Kong because the Hospital Authority treats all patients with suspected COVID-19 free of charge, which may attract an increase in cross-border medical tourism. Eichner et $\mathrm{al}^{15}$ also assumed that no other pandemic control measures would be used, whereas a package of public health interventions have been implemented in Hong Kong in response to COVID-19. ${ }^{16}$ Finally, Eichner et $\mathrm{al}^{15}$ found missing and suboptimal travel data from island nations, to such an extent that data from different years had to be used to extrapolate total annual traveller numbers. In Chong and Zee's clinical model study, ${ }^{14}$ although they assumed that all identified cases accepted voluntary quarantine, they did not specify their definitions of $90 \%$ and $99 \%$ travel restrictions. This could affect the comparability of studies to the actual situation, as closure of points of entry is a dynamic process with travellers changing between different means of entry as long as there is no complete closure of borders. The lack of observational and experimental studies also leads to difficulty for policymakers to take reference. There have been proposals of novel decision support tools that simulate real-life situations more comprehensively. ${ }^{17}$ These tools, however, require further validation.

In consideration of the limitations of these models, we recommend further research. First, with increasing computational power, more comprehensive mathematical models could be built to simulate real-life situations more accurately, taking into account the interactions between different public health measures, as well as heterogeneous mixing of population demographics. Second, there is a need for an international framework outlining the ways, timing, and magnitude of travel restrictions according to the stage of an outbreak (recent outbreak vs established pandemic). Finally, decision support tools should be further evaluated and validated.

In conclusion, extensive travel restrictions should be considered only in conjunction with other public health measures in an emerging pandemic. In isolation, such restrictions may not effectively contain an epidemic, but they can delay its spread and thus provide a buffer for the design, resourcing, and implementation of contingency plans. We hope that this commentary aids our policymakers in formulating public health decisions. We also urge the general public to comply with isolation, quarantine, social distancing, and proper personal hygiene measures in order to help contain the COVID-19 pandemic.

\section{Author contributions}

Concept or design: W Xue.

Acquisition of data: All authors.

Analysis or interpretation of data: All authors.

Drafting of manuscript: W Xue.

Critical revision of the manuscript for important intellectual content: All authors.

All authors had full access to the data, contributed to the study, approved the final version for publication, and take responsibility for its accuracy and integrity.

\section{Conflicts of interest}

All authors have disclosed no conflicts of interest.

\section{Acknowledgement}

We would like to thank Professor Jean-hee Kim from The Jockey Club School of Public Health and Primary Care for guiding us through the writing of this review. We would also like to thank our classmate Mr Yiu-hei See for helpful discussions leading to significant improvements in this manuscript.

\section{Funding/support}

This commentary received no specific grant from any funding agency in the public, commercial, or not-for-profit sectors.

\section{References}

1. Hong Kong SAR Government. CE announces activation of Emergency Response Level in relation to novel coronavirus infection (with photo). 26 January 2020. Available from: https://www.info.gov.hk/gia/general/202001/26/ P2020012600087.htm. Accessed 21 Feb 2020.

2. Centre for Health Protection, Hong Kong SAR Government. Preparedness and response plan for novel infectious disease of public health significance. January 2020. Available from: https://www.chp.gov.hk/files/ pdf/govt_preparedness_and_response_plan_for_novel_ infectious_disease_of_public_health_significance_eng.pdf. Accessed 21 Feb 2020.

3. Hong Kong SAR Government. Scientific committees under CHP review control strategy for novel coronavirus infection. 17 February 2020. Available from: https://www. info.gov.hk/gia/general/202002/17/P2020021700723.htm. Accessed 21 Feb 2020.

4. Wong C. HK to shut almost all crossings with the mainland. 3 February 2020. Available from: https://news.rthk.hk/ rthk/en/component/k2/1506394-20200203.htm. Accessed $21 \mathrm{Feb} 2020$

5. Cheung T, Sum LK, Lau C, Chan HH. Coronavirus: Hong Kong faces escalated medical strike despite government move to expand border closures. 3 February 2020. 
Available from: https://www.scmp.com/news/hong-kong/ health-environment/article/3048738/coronavirus-hongkong-leader-carrie-lam-declares. Accessed 21 Feb 2020.

6. Hong Kong SAR Government. Government announces enhancements to anti-epidemic measures in four aspects. 24 March 2020. Available from: https://www.info.gov.hk/ gia/general/202003/24/P2020032400050.htm. Accessed 2 Apr 2020.

7. World Health Organization. International Health Regulations (2005), third edition. 2016. Available from: https://apps.who.int/iris/bitstream/ handle/10665/246107/9789241580496-eng.pdf;jsessionid $=$ CA3FEE88ED365715621F2C1BA85D2F2F sequence $=1$. Accessed 21 Feb 2020

8. World Health Organization. Statement on the meeting of the International Health Regulations (2005) Emergency Committee regarding the outbreak of novel coronavirus (2019-nCoV). 23 Jan 2020. Available from: https://www. who.int/news-room/detail/23-01-2020-statement-on-themeeting-of-the-international-health-regulations-(2005)emergency-committee-regarding-the-outbreak-of-novelcoronavirus-(2019-ncov). Accessed 10 May 2020.

9. Liu Y, Gayle AA, Wilder-Smith A, Rocklöv J. The reproductive number of COVID-19 is higher compared to SARS coronavirus. J Travel Med 2020;27(2).pii: taaa021.

10. Mateus AL, Otete HE, Beck CR, Dolan GP, Nguyen-VanTam JS. Effectiveness of travel restrictions in the rapid containment of human influenza: a systematic review. Bull World Health Organ 2014;92:868-80D.

11. Huizer YL, Swaan CM, Leitmeyer KC, Timen A. Usefulness and applicability of infectious disease control measures in air travel: a review. Travel Med Infect Dis 2015;13:19-30.

12. Rashid H, Ridda I, King C, et al. Evidence compendium and advice on social distancing and other related measures for response to an influenza pandemic. Paediatr Respir Rev 2015;16:119-26.

13. Cooper BS, Pitman RJ, Edmunds WJ, Gay NJ. Delaying the international spread of pandemic influenza. PLoS Med 2006;3:e212.

14. Chong KC, Zee BCY. Modeling the impact of air, sea, and land travel restrictions supplemented by other interventions on the emergence of a new influenza pandemic virus. BMC Infect Dis 2012;12:309.

15. Eichner M, Schwehm M, Wilson N, Baker MG. Small islands and pandemic influenza: Potential benefits and limitations of travel volume reduction as a border control measure. BMC Infect Dis 2009;9:160.

16. Cowling BJ, Ali ST, Ng TW, et al. Impact assessment of non-pharmaceutical interventions against coronavirus disease 2019 and influenza in Hong Kong: an observational study. Lancet Public Health 2020;5:e279-88.

17. Zlojutro A, Rey D, Gardner L. A decision-support framework to optimize border control for global outbreak mitigation. Sci Rep 2019;9:2216. 